\title{
Change in bone mineral density during adjuvant chemotherapy for early-stage breast cancer
}

\author{
Carina Ørts Christensen ${ }^{1,2}$ • Deirdre Cronin-Fenton ${ }^{3}$ - Trine Frøslev ${ }^{3}$. \\ Anne Pernille Hermann ${ }^{2,4}$ - Marianne Ewertz ${ }^{1,2}$
}

Received: 14 March 2016/Accepted: 25 April 2016/Published online: 5 May 2016

(C) The Author(s) 2016. This article is published with open access at Springerlink.com

\begin{abstract}
Purpose Adjuvant chemotherapy has been associated with loss of bone mineral density (BMD) either as a direct effect or due to glucocorticoids used as supportive care medication. A prospective cohort study was conducted to evaluate changes in BMD from baseline to right after completion of chemotherapy, i.e., 4 months.

Methods Dual-imaging X-ray absorptiometry (DXA) was performed at baseline and after completing anthracyclineand taxane-based chemotherapy to measure BMD in the spine, hip, and forearm in early-stage breast cancer patients. High-dose prednisolone was used at three weekly intervals to reduce nausea and vomiting. Patients were advised a daily calcium/vitamin D supplement. Linear regression was used to assess mean percentage change in BMD and $95 \%$ confidence intervals $(95 \% \mathrm{CI})$ according to doses of prednisolone, menopausal status, smoking, and BMI.

Results Eight patients were excluded: seven because of initiation of bisphosphonate treatment due to osteoporosis at baseline, and one had non-interpretable DXA. The final cohort included 97 patients with a mean age of 53 years (range 34-72). Mean cumulative prednisolone dose was $1308 \mathrm{mg}(95 \% \mathrm{CI}$
\end{abstract}

Carina Ørts Christensen

Carina.Oerts.Christensen@rsyd.dk

1 Department of Oncology, Odense University Hospital, Sdr. Boulevard 29, DK-5000 Odense C, Denmark

2 Institute of Clinical Research, University of Southern Denmark, Winsløwparken 19, 5000 Odense C, Denmark

3 Department of Clinical Epidemiology, Aarhus University Hospital, Olof Palmes Allé 43-45, 8200 Aarhus N, Denmark

4 Department of Endocrinology, Odense University Hospital, Sdr. Boulevard 29, 5000 Odense C, Denmark
1255; 1362). BMD increased $1.36 \%$ (95\% CI $0.7 ; 2.0$, $p<0.001)$ in the spine and $1.27 \%(95 \%$ CI $0.9 ; 1.7$, $p<0.001)$ in the hip. Forearm BMD did not change. Postmenopausal women had increases in spine BMD of $2.35 \%$ (95\% CI 1.1; 3.6, $p<0.001)$ compared to premenopausal women. The spine BMD of current smokers decreased $1.67 \%(95 \% \mathrm{CI}-3.3 ;-0.1, p=0.04)$ compared to never/ former smokers.

Conclusions Adjuvant chemotherapy supplemented with prednisolone was not associated with loss of BMD. Postmenopausal women gained bone mass, whereas current smokers lost bone mass.

Keywords Breast cancer · Adjuvant chemotherapy · Osteoporosis · Bone mineral density $\cdot$ Glucocorticoids

\section{Background}

Breast cancer is the most frequent malignant disease among women worldwide with an estimated 1.67 million new cases diagnosed in 2012 ( $25 \%$ of all cancers in women) and the fifth most common cause of death from cancer (522,000 deaths) [1]. Survival after breast cancer has improved substantially over the past 30-40 years [2] which is likely to be explained by earlier diagnosis via mammography screening and by advances in cancer-directed treatment [3]. Today, more than $90 \%$ of patients with early-stage breast cancer are allocated to adjuvant medical treatment with chemotherapy, anti-HER2treatment, and endocrine therapy depending on the biomarker profile of the primary tumor [4]. Since more than $80 \%$ of breast cancer patients are expected to live for 10 years or longer, it is increasingly important to focus on potential harmful late-effects of the cancer treatment, such as osteoporosis. 
Osteoporosis is characterized by reduced bone mass, deterioration of the bone micro-architecture, and an increased risk of fragility fractures. It affects millions of people worldwide, with the highest prevalence among postmenopausal women. The gold standard for evaluating osteoporosis is measuring bone mineral density (BMD) by dual energy X-ray absorptiometry (DXA), which measures the bone in two dimensions [5].

There are several ways in which breast cancer chemotherapy can increase the risk of osteoporosis but in general, the evidence is sparse. It can induce premature menopause with menopause occurring on average 10 years earlier than normal [6]. We have identified a total of four studies, including 41 to 53 premenopausal breast cancer patients, who received chemotherapy with CMF (cyclophosphamide, methotrexate, fluorouracil) or anthracycline-cyclophosphamide regimens (AC) with measurements of BMD at baseline and 6 months later [7-10]. They demonstrated decreases in BMD in the lumbar spine of $1-4 \%$. It has been suggested that the bone loss may be associated with supportive care medication such as corticosteroids which are the most common cause of secondary osteoporosis with a 7-17-fold increased risk of fractures with daily doses of $10 \mathrm{mg}$ for 3 months [11]. However, women undergoing chemotherapy receive much higher glucocorticoid doses albeit for short durations. Based on 16 patients with Graves' ophthalmopathy, increases in BMD of $3 \%$ were found for treatment with high-dose glucocorticoids given as intravenous pulse-therapy, whereas BMD decreased $2.7 \%$ in patients who received high-dose oral glucocorticoids continuously [12].

We conducted a prospective cohort study to evaluate the effect of adjuvant chemotherapy supplemented with highdose glucocorticoids (prednisolone) on BMD among patients with early-stage breast cancer. We evaluated the combined effect of chemotherapy and prednisolone in the spine, hip, and forearm BMD from baseline to completion of adjuvant chemotherapy.

\section{Material and methods}

\section{Patients}

We recruited women aged 18 years or older diagnosed with histologically verified early-stage breast cancer who underwent surgery (mastectomy or lumpectomy) with axillary node excision (sentinel node or axillary dissection). Patients with inflammatory breast cancer, locally advanced or disseminated breast cancer, or primarily unresectable breast carcinoma were excluded. Patients were also excluded if diagnosed with any other malignancy within the past 5 years that required chemotherapy, had a pre-existing diagnosis of osteoporosis, or currently received systemic treatment with steroids. Women, who for various reasons, were deemed incapable of participating in the study due to psychiatric illness, difficulties understanding the Danish language, or physically unable to lie still when the DXA scan was performed were also excluded.

Patients were referred to the Department of Oncology, Odense University Hospital (OUH), Denmark, for adjuvant medical treatment from September 1, 2013 through August 31, 2014. They were offered a DXA scan at baseline before their first cycle of chemotherapy, and a second DXA scan approximately 3 weeks after their last cycle of chemotherapy. To be included in the final analyses, patients had to complete both DXA scans, receive at least five cycles of adjuvant chemotherapy, and not start bisphosphonate treatment for osteoporosis during chemotherapy.

Informed consent was obtained from all the participants. This study was approved by the Danish Data Protection Board (ID 2008-58-0035) and ethics committee in Region of Southern Denmark (Project ID S-20130065).

\section{Chemotherapy}

In the majority of the patients, adjuvant chemotherapy consisted of three cycles of epirubicin $\left(90 \mathrm{mg} / \mathrm{m}^{2}\right)$ and cyclophosphamide $\left(600 \mathrm{mg} / \mathrm{m}^{2}\right)$ (EC) followed by three cycles of docetaxel $\left(100 \mathrm{mg} / \mathrm{m}^{2}\right)$ intravenously on day one at three weekly intervals, while some received two to six cycles of $\mathrm{EC}$ or docetaxel. There were no statistically significant differences in baseline characteristics between these two patient groups (data not shown). During EC chemotherapy, glucocorticoids were given as anti-emetic prophylaxis with a typical dose of $175 \mathrm{mg}$ prednisolone for one cycle of EC, i.e., $525 \mathrm{mg}$ in total for three cycles. During one cycle of docetaxel, patients received a standard dose of prednisolone $100 \mathrm{mg} /$ day for 3 days, i.e., $300 \mathrm{mg} / \mathrm{cycle}$, in total $900 \mathrm{mg}$ for three cycles. Provided that patients did not need additional prednisolone beyond the amount given during chemotherapy, patients received in total $1425 \mathrm{mg}$ prednisolone over an 18 -week treatment period.

From March 2014, new guidelines were introduced at the Department of Oncology, OUH, regarding anti-emetic treatment in breast cancer patients. Thus, patients received $75 \mathrm{mg}$ prednisolone instead of $175 \mathrm{mg}$ prednisolone at each cycle of EC. This resulted in a reduction in the total prednisolone dose to $1125 \mathrm{mg}$ prednisolone over the 18 -week treatment period for the adjuvant regimen. All patients were advised to take a daily supplement of calcium $(800 \mathrm{mg})$ and vitamin D $(20 \mu \mathrm{g})$ while undergoing chemotherapy. No patients received concomitant endocrine treatment with their chemotherapy.

\section{Data sources}

Baseline data were abstracted from the patient records on date and type of surgery, co-morbidity, prior cancers, regular 
medication, menopause, tobacco consumption, adjuvant cancer-directed treatments, number of treatment cycles, and anti-emetic treatment with glucocorticoids. Data were abstracted from the pathology report on tumor size, histological type and grade, estrogen receptor (ER) status (\% positivity), human epidermal growth factor receptor 2 (HER-2) status, and nodal status. Data were derived directly from the DXA scanner at the Osteoporosis Clinic, Department of Endocrinology, OUH, and included dates of baseline and follow-up scans, height, weight, T- and Z-scores, area (g), bone mineral content $\left(\mathrm{cm}^{2}\right)$, and BMD $\left(\mathrm{g} / \mathrm{cm}^{2}\right)$ in the spine, hip, and forearm.

\section{Bone densitometry}

BMD measurements of the lumbar spine (L1-L4), left hip, and left forearm were obtained using Hologic Discovery QDR, Scanner ID: 82245. All scans were performed by specially trained personnel, and quality standards of the scanner were tested daily with a "Hologic Spine Phantom" ID: 13520 with a median BMD value of 0.974 (0.9594-0.9887). Coefficients of variation (CV) of the BMD measurements were 1.025 and $0.875 \%$ for the lumbar spine and hip, respectively.

Osteoporosis was defined by the World Health Organization (WHO) as a BMD below a certain value, i.e., a T-score for BMD less than 2.5 standard deviations (SDs) below the mean value expected for a young healthy female adult either in the spine and/or the hip. The relative BMD value, the Z-score, describes the number of SDs by which the BMD in an individual differs from the mean value expected for age and sex [5]. Spine T- and Z-scores were calculated with the Hologic manufacturer's reference ranges, and for the hip region, the National Health and Nutrition Examination Survey (NHANES) III reference ranges were used [13].

\section{Exposure variables}

The cumulative dose of prednisolone was calculated as follows: the total dose of prednisolone received during chemotherapy was calculated as the sum of each prednisolone dose administered during each cycle of chemotherapy. In case of an allergic reaction to chemotherapy, the patient received additional methylprednisolone in the acute phase. The dose of methylprednisolone was converted to prednisolone equivalent doses, i.e., multiplying the dose of methylprednisolone by the conversion factor 1.25. The cumulative dose of prednisolone also included any additional prednisolone administered to patients in the 3-week periods between each cycle of chemotherapy. Women who at diagnosis had a menstrual period within the last 12 months were categorized as premenopausal. The others were categorized postmenopausal. Body mass index (BMI) was calculated as weight in kilograms divided by the square of the height in meters. BMI was categorized according to World Health Organization (WHO) criteria as normal (less than 25), overweight (25-30), or obese (30 or more). Patients were categorized into two categories of smoking: current or never/former smokers.

\section{Statistical analyses}

Baseline BMD at each of the three anatomic sites was checked for normality by use of Shapiro-Wilks test and found to be normally distributed. Percentage change in BMD was calculated as (BMD at follow-up-BMD at baseline)/BMD at baseline $\times 100 \%$ in the spine, hip, and forearm, respectively. Categorical data were described using frequencies and percentages. Continuous data were described using means \pm standard deviations. We used uni- and multivariate linear regression to test the association between percentage change in BMD of the spine, hip, and forearm by different factors hypothesized to impact BMD either in a positive (e.g., BMI) or negative (e.g., cumulative dose of prednisolone, menopausal status, and smoking) direction. In the full model, we adjusted for all the factors. We used linear regression to compute the mean percentage change in $\mathrm{BMD}$, and $95 \%$ confidence intervals $(95 \% \mathrm{CI})$ for the spine, hip, and forearm BMD. All statistical analyses were carried out using STATA/IC 14.0.

\section{Results}

The study consort diagram is shown in Fig. 1. Among 168 potentially eligible breast cancer patients, 36 did not meet the inclusion criteria. A further 21 patients with a mean age of 51 (range 31-73) years withdrew informed consent or had no baseline DXA scan. One hundred and five out of 111 patients (95\%) completed both the baseline and the second DXA scan at completion of chemotherapy. The entire study population had mean Z-scores of $0.3,0.2$, and 0.2 in the lumbar spine, hip and forearm, respectively (Table 1$)$. Ten patients (9\%) were diagnosed with osteoporosis at baseline with a mean T-score of $-2.8(95 \% \mathrm{CI}-3.1 ;-2.5)$ in the spine and $-1.9(95 \% \mathrm{CI}$ $-2.2 ;-1.7)$ in the hip. Seven patients with a mean age of 56 (range 35-65) years were excluded from further analyses due to bisphosphonate treatment during chemotherapy, and one patient due to an unreadable baseline DXA. For all characteristics, these patients were similar to the other patients.

A total of 97 patients were included in the final analyses. Their mean age was 53 (range 34-72) years, and 8 of the patients were younger than 40 years. Most tumors (91\%) were invasive ductal carcinomas, with $81 \%$ estrogen receptor positive, $17 \%$ HER-2 positive, and $39 \%$ lymph node positive. About $24 \%$ of patients had a BMI above 30, and $18 \%$ were current smokers (Table 1). At baseline, no patients were treated with systemic glucocorticoids but $13 \%$ were using 


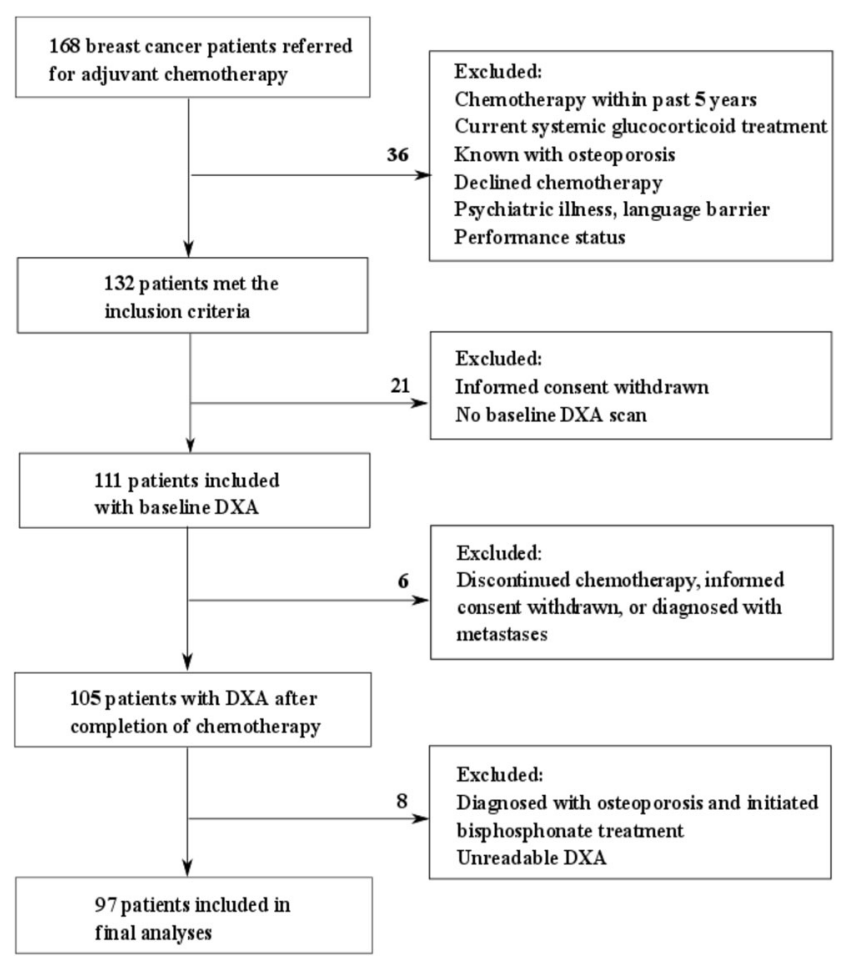

Fig. 1 Consort diagram of the study population

inhaled corticosteroids, nose sprays, crème, or suppositories with corticosteroids either on a regular basis or as required. Four patients had an allergic reaction related to docetaxel and received additional methylprednisolone in the acute phase.

During chemotherapy, patients received a median total cumulative prednisolone dose of $1325 \mathrm{mg}$ with $90 \%$ of patients receiving at least $1125 \mathrm{mg}$ (range 475-2046 mg). Mean prednisolone dose was 1308 mg (95\% CI 1255; 1362). In uni- and multivariate analyses, no statistically significant associations were found between cumulative dose of prednisolone and percentage change in BMD at all three anatomic sites.

At baseline, $55 \%$ had a normal BMD, $42 \%$ had osteopenia, and $3 \%$ were osteoporotic. Mean BMD at baseline was $0.98 \mathrm{~g} / \mathrm{cm}^{2}(95 \% \mathrm{CI} 0.96 ; 1.01)$ for the spine, $0.90 \mathrm{~g} /$ $\mathrm{cm}^{2}(95 \% \mathrm{CI} 0.87 ; 0.92)$ for the hip, and $0.65 \mathrm{~g} / \mathrm{cm}^{2}(95 \% \mathrm{CI}$ $0.64 ; 0.67)$ for the forearm. Mean time interval from baseline to the second DXA scan was 4.4 (range 3.6-6.3) months. Increases were observed in spine BMD of $1.36 \%(95 \% \mathrm{CI}$ $0.7 ; 2.0, p<0.001)$ and hip BMD of $1.27 \%$ (95 \% CI 0.9; 1.7 , $p<0.001)$ while forearm BMD did not change $(-0.19 \%, 95 \%$ CI $-0.7 ; 0.3, p=0.5$ ) (Fig. 2).

Table 2 shows that no change in spine BMD was observed in premenopausal women whereas there was a significant increase of $2.42 \%$ among postmenopausal women. Adjusting for the effects of other variables in multivariate analyses, the significant increase in spine BMD of $2.35 \%$ (95\% CI $1.1 ; 3.6, p<0.001)$ persisted in postmenopausal women compared with premenopausal women. Among current smokers BMD decreased $1.67 \%$ (95\% CI -3.3 ; $-0.1, p=0.04)$ compared with never/former smokers. The multivariate analyses did not reveal any significant association between BMI and BMD. No significant associations were detected between hip and forearm BMD and the investigated characteristics (data not shown).

\section{Discussion}

The literature indicates that continuous use of glucocorticoids is associated with loss of bone mass. However, contrary to expectation, we observed no significant changes in BMD associated with prednisolone dose. A bone loss of $10 \%$ corresponds to a reduction of $1 \mathrm{SD}$, which is expected to increase the risk of fractures by a factor two to three [14]. Glucocorticoids have shown to increase bone resorption and decrease bone formation [15]. This effect seems to persist throughout the duration of glucocorticoid treatment. Moreover, continuous use of glucocorticoid therapy is associated with increased risk of fracture with increasing dose and duration of treatment, particularly, within the first 3 to 6 months. A few months after cessation of the treatment, a corresponding rapid decrease is seen in fracture risk [16]. Based on 191,752 patients from the UK General Practice Database who were followed for 10 years, De Vries et al. reported a strong association between continuous daily doses of oral glucocorticoids (cumulative exposure $>1 \mathrm{~g}$ of prednisolone) and risk of fracture, whereas patients who received intermittent high-dose oral glucocorticoids were associated with a substantial lower risk of fractures [17].

Patients in our study received a mean prednisolone dose of $1304 \mathrm{mg}$ administered at intervals with chemotherapy. Since no bone loss was observed, our data demonstrate that such a chemotherapy regimen seems safe. This is reassuring because glucocorticoids are essential in preventing chemotherapyinduced nausea and vomiting [18]. We investigated a limited period of 4 months. During this time, no fractures were reported. However, we cannot rule out the possibility that patients, due to exposure of glucocorticoids, may be at increased risk of fractures, since other studies have reported increased fracture risk caused by deterioration of bone quality, which is not captured by BMD $[19,20]$.

Interestingly, we found increases in both spine and hip BMD from baseline to completion of adjuvant chemotherapy. In spine BMD, the increase was statistically significant among postmenopausal women whereas current smokers had a significant decrease compared to never/former smokers.

Animal studies have shown that cytotoxic agents such as doxorubicin and methotrexate reduce bone formation by reducing osteoblastic activity in rats $[21,22]$. Four studies reported changes in spine and hip BMD in breast cancer patients during a 6-month period after start of chemotherapy 
Table 1 Characteristics of the study population

\begin{tabular}{|c|c|c|}
\hline & Patients in total $N=111(\%)$ & Patients in final analyses $N=97(\%)$ \\
\hline \multicolumn{3}{|l|}{ Age at diagnosis } \\
\hline 50 & $32(29)$ & $30(31)$ \\
\hline $50-59$ & $53(48)$ & $47(48)$ \\
\hline$\geq 60$ & $26(23)$ & $20(21)$ \\
\hline \multicolumn{3}{|l|}{ Menopausal status } \\
\hline Premenopausal & $45(41)$ & $43(44)$ \\
\hline Postmenopausal & $66(59)$ & $54(56)$ \\
\hline \multicolumn{3}{|l|}{ Type of surgery } \\
\hline Lumpectomy & $63(57)$ & $56(58)$ \\
\hline Mastectomy & $48(43)$ & $41(42)$ \\
\hline \multicolumn{3}{|l|}{ Type of carcinoma } \\
\hline Ductal & $101(91)$ & $88(91)$ \\
\hline Lobular & $4(4)$ & $4(4)$ \\
\hline Others & $6(5)$ & $5(5)$ \\
\hline \multicolumn{3}{|l|}{ Tumorsize } \\
\hline $0-9 \mathrm{~mm}$ & $6(5)$ & $4(4)$ \\
\hline $10-19 \mathrm{~mm}$ & $51(46)$ & $43(44)$ \\
\hline $20+\mathrm{mm}$ & $54(49)$ & $50(52)$ \\
\hline \multicolumn{3}{|l|}{ Histological grade } \\
\hline Low (I) & $15(14)$ & $11(11)$ \\
\hline Moderate (II) & $36(32)$ & $30(31)$ \\
\hline High (III) & $54(49)$ & $51(53)$ \\
\hline (Unknown) & $6(5)$ & $5(5)$ \\
\hline \multicolumn{3}{|l|}{ Estrogen status } \\
\hline ER negative $0 \%$ & $19(17)$ & $18(19)$ \\
\hline ER poor $1-10 \%$ & $6(5)$ & $6(6)$ \\
\hline ER positive $10 \%$ & $86(78)$ & $73(75)$ \\
\hline \multicolumn{3}{|l|}{ HER2 status } \\
\hline HER2 negative & $92(83)$ & $81(83)$ \\
\hline HER2 positive & $19(17)$ & $16(17)$ \\
\hline \multicolumn{3}{|l|}{ Nodal status } \\
\hline Node negative & $67(60)$ & $59(61)$ \\
\hline Node positive & $44(40)$ & $38(39)$ \\
\hline \multicolumn{3}{|l|}{ Body mass index $\left(\mathrm{kg} / \mathrm{m}^{2}\right)$} \\
\hline 25 normal & $43(39)$ & $38(39)$ \\
\hline 25-30 overweight & $38(34)$ & $36(37)$ \\
\hline 30 obese & $30(27)$ & $23(24)$ \\
\hline \multicolumn{3}{|l|}{ Smoking status } \\
\hline Never/former smokers & $91(82)$ & $80(82)$ \\
\hline Current smokers & $20(18)$ & $17(18)$ \\
\hline \multicolumn{3}{|l|}{ Baseline T-score } \\
\hline Spine & $-0.7 \pm 1.3^{\mathrm{bc}}$ & $-0.5 \pm 1.2^{\mathrm{b}}$ \\
\hline Hip & $-0.5 \pm 1.1^{\mathrm{a}}$ & $-0.4 \pm 1.0^{\mathrm{a}}$ \\
\hline Forearm & $-0.8 \pm 1.0^{\mathrm{a}}$ & $-0.7 \pm 1.0^{\mathrm{a}}$ \\
\hline \multicolumn{3}{|l|}{ Baseline Z-score } \\
\hline Spine & $0.3 \pm 1.3^{\mathrm{ab}}$ & $0.4 \pm 1.2^{\mathrm{a}}$ \\
\hline Hip & $0.2 \pm 1.1^{\mathrm{a}}$ & $0.3 \pm 1.1^{\mathrm{a}}$ \\
\hline Forearm & $0.2 \pm 1.0^{\mathrm{a}}$ & $0.3 \pm 0.9^{\mathrm{a}}$ \\
\hline
\end{tabular}

${ }^{\mathrm{a}}$ Mean \pm standard deviation (SD)

${ }^{\mathrm{b}} N=110$ patients

[7-10]. Based on 41 to 53 premenopausal patients who received CMF- or AC-based chemotherapy, decreases were reported in BMD of $1-4 \%$ in the spine and -0.7 to $2.6 \%$ in the hip. Cameron et al. reported on 41 premenopausal women with decreases in BMD of $4 \%$ in the spine and $2 \%$ in the hip [10]. Nine patients received chemotherapy with docetaxel. All patients received glucocorticoids (dexamethasone) as antiemetic treatment. However, the dose and regimen of glucocorticoids was not stated. Nor was it mentioned whether the patients received supplements of calcium and vitamin D.
In our study, the time interval between baseline and follow-up DXA was 4.4 months, and patients represented a mix of both pre- and postmenopausal women. Since our finding is not in line with previous findings, we cannot rule out that the rather short time of follow-up may be a possible explanation. However, our findings may be explained by the calcium and vitamin D given in our study, which is known to affect bone turnover rate in persons with low calcium intake or low calcium absorption, e.g., postmenopausal women [23]. 
Fig. 2 Changes in median $\mathrm{BMD}$ and interquartile ranges for DXA scans before and after chemotherapy in 97 Danish patients with early-stage breast cancer

\section{Changes in BMD}

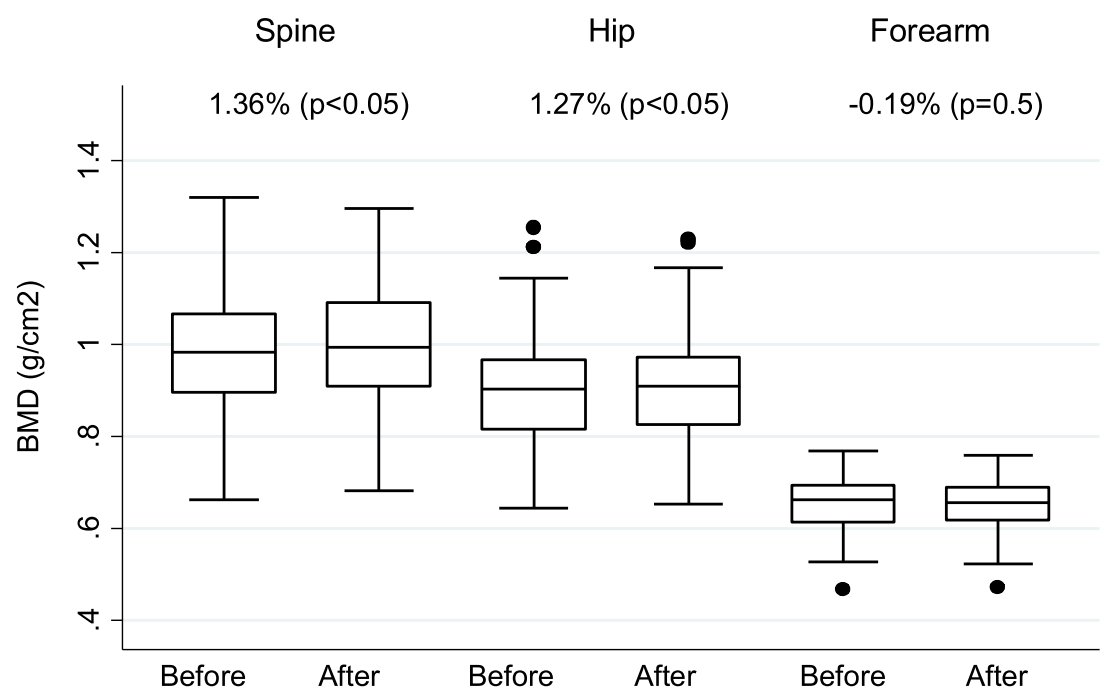

Physiologically, premenopausal women have a low bone turnover compared to postmenopausal women who have a higher bone turnover. Moreover, the spine has the largest bone surface, and it consists primarily of cancellous bone. Thus, the spine is the location where changes in bone turnover are first seen [24]. This correlates well with our results detected in the spine. Moreover, the significant increases in spine BMD seen in older women are compatible with normal physiology of the bones. When women enter menopause, they undergo two phases of bone loss. An initial accelerated phase of predominantly cancellous bone loss that declines rapidly over $4-8$ years which subsequently merges with a slow phase that continues indefinitely [25]. The majority of premenopausal women who receive chemotherapy experience chemotherapy-induced ovarian failure (CIOF) with rapid decreases in estrogen levels and a shift in bone turnover from a low to a high state [26]. This is seen as a decrease in BMD measured by DXA. Thus, bone turnover is driven by the withdrawal of estrogen [27]. In contrast, postmenopausal women are in the slow phase of bone loss. Instead, they experience an age-related insufficient calcium absorption from the intestines, which causes an increase in parathyroid hormone (PTH) with resorption of calcium from the bones to maintain a systemic steady state of calcium in the blood. Thus, PTH is the dominating mechanism associated to bone turnover in postmenopausal women [27]. When postmenopausal women receive calcium and vitamin D supplements, bone turnover decreases due to closing of the gaps of remodeling. This is seen as an increase in BMD [27].

At follow-up, the majority (72\%) of patients had received a daily calcium and vitamin D supplement during chemotherapy,

Table 2 Absolute $(\triangle B M D)$ and relative (Coef.) changes in spine BMD from baseline to completion of adjuvant chemotherapy in 97 Danish patients with early-stage breast cancer

\begin{tabular}{|c|c|c|c|c|c|c|c|c|c|}
\hline \multirow{2}{*}{$\begin{array}{l}\text { Lumbar spine } \\
\text { Co-variates }\end{array}$} & \multirow[b]{2}{*}{ Number } & \multirow[b]{2}{*}{$\Delta \mathrm{BMD}^{\mathrm{a}}(\%)$} & \multirow[b]{2}{*}{$95 \% \mathrm{CI}$} & \multicolumn{3}{|c|}{ Univariate analyses } & \multicolumn{3}{|c|}{ Multivariate analyses ${ }^{\mathrm{c}}$} \\
\hline & & & & Coef. $^{\mathrm{b}}(\%)$ & $P$ value & $95 \% \mathrm{CI}$ & Coef. $(\%)$ & $P$ value & $95 \% \mathrm{CI}$ \\
\hline Prednisolone pr. $1 \mathrm{~g}$ & 97 & 0.97 & $-1.5 ; 3.4$ & 0.97 & 0.43 & $-1.5 ; 3.4$ & 1.57 & 0.17 & $-0.7 ; 3.8$ \\
\hline Premenopausal at diagnosis & 43 & 0.03 & $-0.8 ; 0.8$ & 0 (ref.) & & & 0 (ref.) & & \\
\hline Postmenopausal at diagnosis & 54 & 2.42 & $1.6 ; 3.3$ & 2.39 & $<0.001$ & $1.2 ; 3.6$ & 2.35 & $<0.001$ & $1.1 ; 3.6$ \\
\hline Never/former smoker & 80 & 1.70 & $1.0 ; 2.4$ & 0 (ref.) & & & 0 (ref.) & & \\
\hline Current smoker & 17 & 0.22 & $-1.5 ; 1.1$ & -1.92 & 0.02 & $-3.6 ;-0.3$ & -1.67 & 0.04 & $-3.3 ;-0.1$ \\
\hline BMI $(<25)$ & 38 & 1.03 & $0.1 ; 1.9$ & 0 (ref.) & & & 0 (ref.) & & \\
\hline BMI (25-30) & 36 & 1.70 & $0.7 ; 2.7$ & 0.67 & 0.37 & $-0.8 ; 2.1$ & 0.19 & 0.78 & $-1.2 ; 1.6$ \\
\hline BMI $(>30)$ & 23 & 1.39 & $-0.3 ; 3.1$ & 0.36 & 0.67 & $-1.3 ; 2.0$ & -0.40 & 0.61 & $-2.0 ; 1.2$ \\
\hline
\end{tabular}

${ }^{\mathrm{a}} \triangle \mathrm{BMD}=$ mean percent change

${ }^{\mathrm{b}}$ Coef. coefficient $=(\mathrm{BMD}$ at follow-up $-\mathrm{BMD}$ at baseline $) / \mathrm{BMD}$ at baseline $\times 100 \%=$ mean percent change in BMD $(\%)$

${ }^{\mathrm{c}}$ Multivariate analyses adjusted for prednisolone, menopausal status, smoking, and BMI 
which most likely has contributed to the increased BMD observed in our study. We examined whether there was a difference in BMD between patients who received calcium and vitamin D supplements and those who did not and noted an increase in spine and hip BMD in both the groups. However, the analyses were based on too few patients to give a meaningful result. The reduction in BMD observed in current smokers fits well with the explanation since one of the deleterious effects of smoking on bone is to reduce intestinal calcium absorption [28].

At baseline, $9 \%$ of patients (10/111 patients) were diagnosed with osteoporosis. In 2010, the prevalence of osteoporosis was estimated to be $21 \%$ in Danish women aged 50 years or more and $5 \%$ in the general population when measuring hip BMD [5]. In another study of 9933 Danish women, the prevalence of osteoporosis was reported to be $14 \%$ when BMD was measured at the spine, hip, or both [29]. Our patients had mean baseline Z-scores greater than zero for all the anatomic sites, which translates into higher BMD values at baseline compared to the female background population of the same age. However, the mean Z-scores may represent an overestimation of BMD, due to possible selection bias of the patients included in the study.

The main strength of our study is the prospective data collection. All eligible patients were enrolled consecutively in the study and had a baseline DXA performed before onset of the first cycle of chemotherapy. Each patient was her own control, and the second DXA was performed on the same DXA scanner approximately 3 weeks after completion of chemotherapy. Only four patients started endocrine treatment before the second DXA was performed.

However, there are some limitations to our study, one of them being that it is a single institution experience limiting the generalizability. We had no reliable information on alcohol consumption, physical activity, or prior hormone replacement therapy which are known to affect bone density in a positive way mostly among postmenopausal women [30-32]. We did not check the compliance to prednisolone prescribed as an anti-emetic treatment, and we were also unable to account for glucocorticoids, prescribed for underlying medical indications. Also, it would have been preferable to include a control group without steroids but it was considered unethical to withhold steroids as anti-emetic treatment from these patients. Finally, unfortunately, we had no measurements of vitamin $\mathrm{D}$ or biochemical markers of bone turnover.

\section{Conclusion}

In summary, contrary to expectation, we found that adjuvant anthracycline- and taxane-based chemotherapy supplemented with supportive therapy (prednisolone) for early-stage breast cancer was not associated with bone loss when supplemented with calcium and vitamin D. Postmenopausal women gained significantly bone mass in the spine, whereas current smokers had a significant bone loss in the spine. It was reassuring, that no significant association was detected between prednisolone dose and changes in BMD. Furthermore, guidelines have changed, and lower total doses are now recommended as anti-emetic prophylaxis allowing the use of corticosteroids to continue in anti-emetic treatment. Our data suggest that in patients who receive chemotherapy, it may not be necessary to perform a DXA before start of chemotherapy, but that it will be safe to postpone it until later.

Acknowledgments Funding for this study was provided by the Region of Southern Denmark; the Department of Oncology, Odense University Hospital; the Department of Endocrinology, Odense University Hospital; the Danish Cancer Society; and the University of Southern Denmark.

A special thanks to all the patients who participated in the study and to the doctors, nurses, and secretaries at the Department of Oncology, Odense University Hospital, Denmark, for each of their contribution to make this project possible.

Also a special thanks to the staff, and in particularly, to Jane Nielsen at the Osteoporosis Clinic, Department of Endocrinology, Odense University Hospital, Denmark.

\section{Compliance with ethical standards}

Conflict of interest The authors declare that they have no competing interests.

Open Access This article is distributed under the terms of the Creative Commons Attribution-NonCommercial 4.0 International License (http:// creativecommons.org/licenses/by-nc/4.0/), which permits any noncommercial use, distribution, and reproduction in any medium, provided you give appropriate credit to the original author(s) and the source, provide a link to the Creative Commons license, and indicate if changes were made.

\section{References}

1. Ferlay J, Soerjomataram I, Dikshit R, Eser S, Mathers C, Rebelo M, Parkin DM, Forman D, Bray F (2015) Cancer incidence and mortality worldwide: sources, methods and major patterns in GLOBOCAN 2012. Int J Cancer 136(5):E359-386. doi:10.1002/ ijc. 29210

2. Howlader N NA, Krapcho M, Garshell J, Miller D, Altekruse SF, Kosary CL, Yu M, Ruhl J, Tatalovich Z,Mariotto A, Lewis DR, Chen HS, Feuer EJ, Cronin KA (eds). SEER Cancer Statistics Review, 1975-2011, National Cancer Institute. Bethesda, MD, http://seer.cancer.gov/csr/1975_2011/, based on November 2013 SEER data submission, posted to the SEER web site, April 2014

3. Tryggvadottir L, Gislum M, Bray F, Klint A, Hakulinen T, Storm HH, Engholm G (2010) Trends in the survival of patients diagnosed with breast cancer in the Nordic countries 1964-2003 followed up to the end of 2006. Acta Oncol 49(5):624-631. doi:10.3109/ 02841860903575323

4. Goldhirsch A, Wood WC, Coates AS, Gelber RD, Thurlimann B, Senn HJ, Panel M (2011) Strategies for subtypes-dealing with the diversity of breast cancer: highlights of the St. Gallen International Expert Consensus on the Primary Therapy of 
Early Breast Cancer 2011. Ann Oncol 22(8):1736-1747. doi: 10.1093/annonc/mdr304

5. Hernlund E, Svedbom A, Ivergard M, Compston J, Cooper C, Stenmark J, McCloskey EV, Jonsson B, Kanis JA (2013) Osteoporosis in the European Union: medical management, epidemiology and economic burden. A report prepared in collaboration with the International Osteoporosis Foundation (IOF) and the European Federation of Pharmaceutical Industry Associations (EFPIA). Arch Osteoporos 8(1-2):136. doi:10. 1007/s11657-013-0136-1

6. Coleman RE, Rathbone E, Brown JE (2013) Management of cancer treatment-induced bone loss. Nat Rev Rheumatol 9(6):365-374. doi:10.1038/nrrheum.2013.36

7. Shapiro C, Manola J, Leboff M (2001) Ovarian failure after adjuvant chemotherapy is associated with rapid bone loss in women with early-stage breast cancer. J Clin Oncol 19(14): 3306-3311

8. Vehmanen L, Saarto T, Risteli J, Risteli L, Blomqvist C, Elomaa I (2004) Short-term intermittent intravenous clodronate in the prevention of bone loss related to chemotherapy-induced ovarian failure. Breast Cancer Res Treat 87(2):181-188. doi:10.1023/ B:BREA.0000041624.00665.4e

9. Hershman DL, McMahon DJ, Crew KD, Cremers S, Irani D, Cucchiara G, Brafman L, Shane E (2008) Zoledronic acid prevents bone loss in premenopausal women undergoing adjuvant chemotherapy for early-stage breast cancer. J Clin Oncol 26(29):4739-4745. doi:10.1200/JCO.2008.16.4707

10. Cameron DA, Douglas S, Brown JE, Anderson RA (2010) Bone mineral density loss during adjuvant chemotherapy in premenopausal women with early breast cancer: is it dependent on oestrogen deficiency? Breast Cancer Res Treat 123(3):805-814. doi:10.1007/s10549-010-0899-7

11. Weinstein RS (2011) Clinical practice. Glucocorticoid-induced bone disease. N Engl J Med 365(1):62-70. doi:10.1056/ NEJMcp1012926

12. Marcocci C, Bartalena L, Tanda ML, Manetti L, Dell'Unto E, Rocchi R, Barbesino G, Mazzi B, Bartolomei MP, Lepri P, Cartei F, Nardi M, Pinchera A (2001) Comparison of the effectiveness and tolerability of intravenous or oral glucocorticoids associated with orbital radiotherapy in the management of severe Graves' ophthalmopathy: results of a prospective, single-blind, randomized study. J Clin Endocrinol Metab 86(8):3562-3567. doi:10.1210/jcem.86.8.7737

13. Looker AC, Wahner HW, Dunn WL, Calvo MS, Harris TB, Heyse SP, Johnston CC Jr, Lindsay R (1998) Updated data on proximal femur bone mineral levels of US adults. Osteoporos Int 8(5):468-489

14. Marshall D, Johnell O, Wedel H (1996) Meta-analysis of how well measures of bone mineral density predict occurrence of osteoporotic fractures. BMJ 312(7041):1254-1259

15. Weinstein RS, Jilka RL, Parfitt AM, Manolagas SC (1998) Inhibition of osteoblastogenesis and promotion of apoptosis of osteoblasts and osteocytes by glucocorticoids. Potential mechanisms of their deleterious effects on bone. J Clin Invest 102(2): 274-282. doi:10.1172/JCI2799

16. Van Staa TP, Leufkens HG, Abenhaim L, Zhang B, Cooper C (2000) Use of oral corticosteroids and risk of fractures. J Bone Miner Res 15(6):993-1000. doi:10.1359/jbmr.2000.15.6.993
17. De Vries F, Bracke M, Leufkens HG, Lammers JW, Cooper C, Van Staa TP (2007) Fracture risk with intermittent high-dose oral glucocorticoid therapy. Arthritis Rheum 56(1):208-214. doi:10.1002/ art.22294

18. Herrstedt J, Rapoport B, Warr D, Roila F, Bria E, Rittenberg C, Hesketh PJ (2011) Acute emesis: moderately emetogenic chemotherapy. Support Care Cancer 19(Suppl 1):S15-23. doi:10.1007/ s00520-010-0951-5

19. Van Staa TP, Laan RF, Barton IP, Cohen S, Reid DM, Cooper C (2003) Bone density threshold and other predictors of vertebral fracture in patients receiving oral glucocorticoid therapy. Arthritis Rheum 48(11):3224-3229. doi:10.1002/art.11283

20. Peel NF, Moore DJ, Barrington NA, Bax DE, Eastell R (1995) Risk of vertebral fracture and relationship to bone mineral density in steroid treated rheumatoid arthritis. Ann Rheum Dis 54(10):801806

21. Pfeilschifter J, Diel IJ (2000) Osteoporosis due to cancer treatment: pathogenesis and management. J Clin Oncol 18(7):1570-1593

22. Wissing MD (2015) Chemotherapy- and irradiation-induced bone loss in adults with solid tumors. Curr Osteoporos Rep 13(3):140 145. doi:10.1007/s11914-015-0266-Z

23. Aloia JF, Vaswani A, Yeh JK, Ross PL, Flaster E, Dilmanian FA (1994) Calcium supplementation with and without hormone replacement therapy to prevent postmenopausal bone loss. Ann Intern Med 120(2):97-103

24. Weinstein RS, Parfitt AM, Marcus R, Greenwald M, Crans G, Muchmore DB (2003) Effects of raloxifene, hormone replacement therapy, and placebo on bone turnover in postmenopausal women. Osteoporos Int 14(10):814-822. doi:10.1007/s00198-003-1434-z

25. Riggs BL, Khosla S, Melton LJ 3rd (2002) Sex steroids and the construction and conservation of the adult skeleton. Endocr Rev 23(3):279-302. doi:10.1210/edrv.23.3.0465

26. Garnero P, Sornay-Rendu E, Chapuy MC, Delmas PD (1996) Increased bone turnover in late postmenopausal women is a major determinant of osteoporosis. J Bone Miner Res 11(3):337-349. doi: 10.1002/jbmr.5650110307

27. Riggs BL, Khosla S, Melton LJ 3rd (1998) A unitary model for involutional osteoporosis: estrogen deficiency causes both type I and type II osteoporosis in postmenopausal women and contributes to bone loss in aging men. J Bone Miner Res 13(5):763-773. doi: 10.1359/jbmr.1998.13.5.763

28. Wong PK, Christie JJ, Wark JD (2007) The effects of smoking on bone health. Clin Sci (Lond) 113(5):233-241. doi:10.1042/ CS20060173

29. Vestergaard P, Rejnmark L, Mosekilde L (2005) Osteoporosis is markedly underdiagnosed: a nationwide study from Denmark. Osteoporos Int 16(2):134-141. doi:10.1007/s00198-004-1680-8

30. Feskanich D, Korrick SA, Greenspan SL, Rosen HN, Colditz GA (1999) Moderate alcohol consumption and bone density among postmenopausal women. J Women's Health 8(1):65-73

31. Karlsson M (2004) Has exercise an antifracture efficacy in women? Scand J Med Sci Sports 14(1):2-15

32. Watts NB, Notelovitz M, Timmons MC, Addison WA, Wiita B, Downey LJ (1995) Comparison of oral estrogens and estrogens plus androgen on bone mineral density, menopausal symptoms, and lipid-lipoprotein profiles in surgical menopause. Obstet Gynecol 85(4):529-537 